\title{
Somatization disorder
}

\author{
MARK W. KETTERER, PHD \\ CHARLES D. BUCKHOLTZ, DO
}

Somatization disorder (SD) is a syndromatic classification that allows a physician to identify more easily patients with a lifelong history of chronic subjective physical complaints that are unverified by objective examinations either at the time of initial presentation or during the subsequent five years. The somaticizing process is believed to be an expression of emotional distress. The most common complaints of SD patients include recurrent pain (site and quality vary), conversion (pseudoneurologic) symptoms, nervousness or depression (or both), sexual and marital discord, and, often, menstrual difficulties. Such patients will generally have a history of repeated hospitalization or surgery. These symptoms are not perceived as mild or unimportant but lead to physician consultation, prescription drug use, and modification of life-style. Such patients are prone to "doctor-shopping" and selfmedication and are at risk for many iatrogenic illnesses. Because they generally are resistant to psychologic explanations for their condition, management aimed at protecting them from the consequences of their behavior is important. A heightened threshold for instituting aggressive diagnostic and treatment procedures is necessary.

Because of medicine's strong biologic orientation $^{1}$ and its roots in Euro-American culture, disorders that encompass the mind-brain/body dichotomy can be uniquely problematic in primary care settings. ${ }^{2-4}$ The mind-brain duality advocated by René Descartes in the 17 th century ${ }^{5,6}$ still dominates the way most educated people conceptualize the relationship between psychologic events and physiologic processes, despite powerful evidence that psychologic phenomena are nothing more, or less, than concomitants of CNS activity. ${ }^{7}$

The Cartesian version of psychoneural relationships has been heuristic in that it has allowed medical science to take on manageable research and clinical tasks rather than being overwhelmed by the

full complexity of human pathophysiology, as occurred prior to the late $1800 \mathrm{~s}^{8}$

Unfortunately, the same set of beliefs can blind practitioners to the role of psychologic processes in generating complaints of physical symptoms. One set of disorders that often confuses mind-brain/ body relationships for the primary care physician are the somatoform disorders.

A patient who chronically reports one or more subjective physical symptoms that cannot be verified by objective evidence has a somatoform disorder. This category includes conversion disorder, somatoform pain disorder, hypochondriasis, body dysmorphic disorder, and somatization disorder. ${ }^{9}$ The term somatoform suggests that the patient's illness has the appearance (or form) of a physical disorder. However, the common feature of somatoform disorders is that there is no demonstrable evidence of organic dysfunction or no known physiologic mechanism for explaining the patient's symptoms, and that there is a reasonable basis for presuming causality by psychologic factors.

It must be remembered that unlike the factitious disorders or malingering, the production of symptoms is not intentional or conscious. Yet the production of symptoms, upon close and detailed scrutiny, almost always will appear to be controlled or influenced by psychosocial consequences.

Although not generally classified as somatoform disorders, traditional psychiatric syndromes, including depression and the anxiety disorders, frequently will be manifested as physical complaints $^{10,11}$ and, thus, they arguably can be so categorized. This is because of the patient's denial (repression, suppression, or misattribution) of psychologic problems, the automatization of cognitive and behavioral coping strategies, ${ }^{7}$ and the attendant physical symptoms of these disorders (fatigue and preoccupation with minor pains in depression, or palpitations, dizziness, dyspnea, or diaphoresis in panic attack).

The best understood of the somatoform disorders is somatization disorder (SD). ${ }^{12-14}$

\section{Terminology}

Because the term hysteria has come to be applied to a personality style, ${ }^{15,16}$ a personality disorder, ${ }^{9,17}$ an acute emotional state, and a mental disorder, ${ }^{12}$ 
recent empiric studies have begun using more concrete criteria and a different terminology to clarify meaning. For example, the personality disorder, which is characterized by overly dramatic, reactive, and intensely expressed behavior and disturbances in interpersonal relationships, now is termed "histrionic." ${ }^{9}$ The mental disorder has come to be known as Briquet's syndrome (after the physician who first described a polysymptomatic patient with a complicated medical history who was not objectively ill ${ }^{18}$ ) or SD.

\section{Epidemiology and demographics}

The prevalence of SD among women in the United States is $0.2 \%$ to $2 \% .^{9}$ Somatization disorder is rarely diagnosed in men. However, on the basis of one study, ${ }^{19} \mathrm{SD}$ was a frequent finding in a primary care outpatient setting. The authors speculate that "...for the average physician, this diagnosis could be made nearly every day that patients are seen."

Available data indicate that SD is a familial disorder. First-degree female relatives of SD patients have a much higher rate of SD (about $10 \%$ to 20\%) than would be expected in the general population. ${ }^{20-24}$ Additionally, male relatives of SD patients have much higher rates of antisocial personality disorder and psychoactive substance abuse than seen in the general population. ${ }^{20-25}$

\section{Etiology}

The presence of a familial factor in the background of SD patients is consistent with both a genetic and environmental etiology. ${ }^{26} \mathrm{As}$ with the other somatoform disorders, it is presumed that unconscious secondary gain (the social consequences of being ill, including decreased expectations of others for work and increased attention) plays a major role in initiating and maintaining the symptomatic picture. That is, patients unknowingly have learned to cope with their own emotional needs (attention, fatigue, loneliness, anger) by becoming "ill" 27 - a strategy that they likely observed was used by their mother, sister, aunt, or grandmother.

Such a coping strategy allows an individual to obtain something they need without having to take interpersonal responsibility for asking overtly. This strategy presumably is adaptive in an interpersonal environment with multiple antisocial, personalitydisordered men and multiple "sick" women. ${ }^{7}$

The patient, it must be emphasized, is unaware that her illnesses serve these psychosocial purposes, and she is highly resistant to any such suggestion. The resistance is assumed to be a product of the unconscious nature of the psychologic mechanism, ${ }^{7}$ fear of stigmatization ("It's all in your head"), and the unconsciously perceived consequence (interpersonal confrontation) of acknowledging the anger, sadness, or other emotion.

\section{Natural history and course}

The onset of chronic physical complaints and symptoms generally occurs prior to age 30 , most often in the second decade of life. The course of the illness generally is either chronic or intermittent. The disorder rarely remits spontaneously; careful history-taking will reveal that seldom does a year pass without the patient seeking some form of medical attention. In a severe case, the patient will be an invalid and will squander her life in a preoccupation with physicians, medications, and symptoms. Psychosocial stressors often appear to be the precipitating event, despite the patient's denial of their relevance. Interestingly, the disorder does not appear to manifest in childhood. It is unknown whether such patients display a propensity for school avoidance or other forms of secondary gain as children.

\section{Signs and symptoms}

SD is characterized by recurrent, multiple physical complaints that cannot be objectively verified but that have led to physician consultation, use of a prescription medication, modification of life-style to accommodate the symptom, or a combination of these. While the list of symptoms SD patients will endorse is endless, most common are recurrent pain (although site and quality vary), conversion (pseudoneurologic) symptoms, nervousness or depression (or both), sexual and marital discord, and repeated hospitalization or surgery.

One early study ${ }^{28}$ listed the astonishing frequency of various signs and symptoms in a group of SD patients (Table 1). A more recent study ${ }^{29}$ reported that SD patients report more physical symptoms than objectively ill patients (with chronic obstructive pulmonary disease or diabetes) while reporting only slightly more psychologic symptoms (Fig 1).

\section{Diagnosis}

Because of the vague and variable nature of presentation, the physician is likely to find historytaking a confusing process with SD patients. A straightforward, sequential history of a principal complaint is almost impossible to obtain. Patients frequently will contradict themselves, and, if confronted about such inconsistencies, they will confabulate at least a marginally plausible explanation.

In trying to reduce the confusion, many physicians latch onto a single symptom to guide treat- 
Evidence directly linking

elevated cholesterol and CAD

made you take a closer look at lipid levels

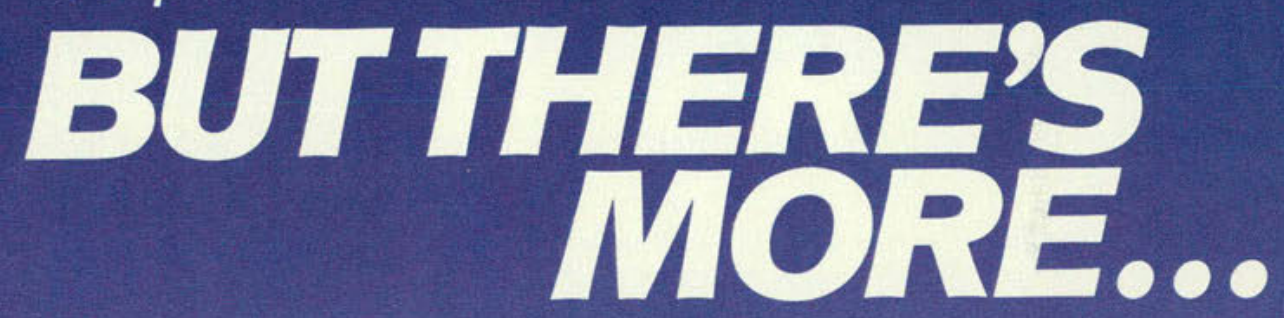


Lorelco is indicated for the reduction of elevated serum cholesterol in patients with primary hypercholesterolemia, as an adjunct to diet.
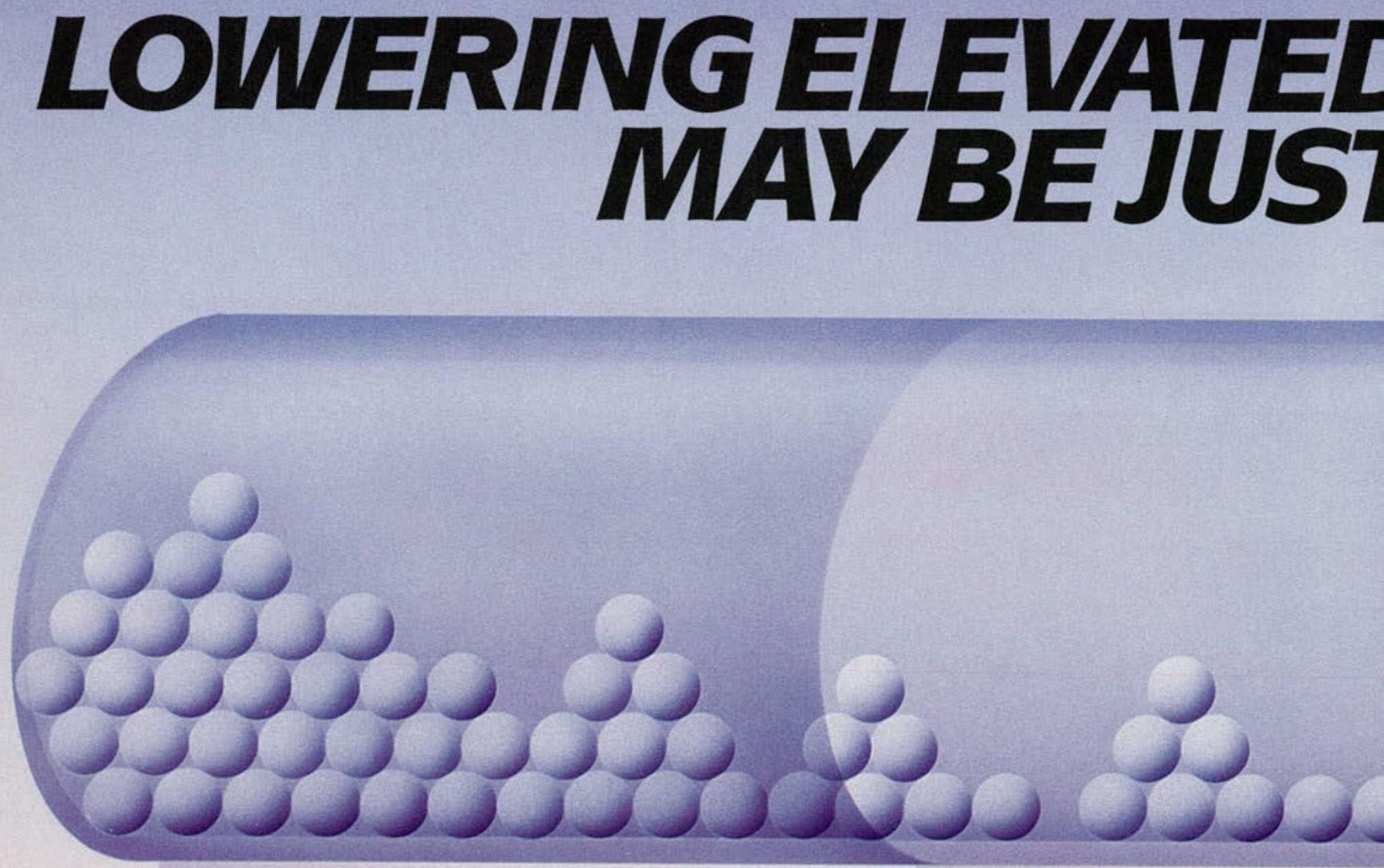

Recent in vitro studies and hum

Lorelco (probucol) offers proven longterm cholesterollowering efficacy*

- Lowers total cholesterol by up to $27 \%^{1,2}$

- Maintains lower levels as proven over a 12-year period ${ }^{3}$

- Increases fractional rate of

LDL catabolism

(See Clinical Pharmacology)

*The effect of probucol-induced reduction of serum cholesterol or triglyceride levels or reduction of $\mathrm{HDL}$-cholesterol levels on morbidity or mortality due to coronary heart disease has not been established.

References: 1.SAfr Med J 1982;62:7-11. 2. Arch Intern Med 1981:141:1428-1432.

3. Data on file, MERREL DOW PHARMACEUTICALS INC. Cincinnati, Ohio 45242

3. Data On File, MERRELL DOW PHARMACEUTICALSINC., Cincinnati, Ohio 452
9553. 4. Am J Cardiol 1988:62:31B-36B. 5. Acherosclerosis 1986:62:209-217.

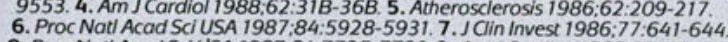

8. Proc Nat Acad Sci USA 1987:84:7725-7729. 9. Am J Cardiol 1988;62:68-12B.

10. Am J Cardiol 1986:57:16 H-21H. 11. Am J Cardiol 1988:62:57B-59B. 12. Am J

Cardiol 1988:62:668-72B. 13. Am J Cardiol 1988:62:73B-76B. 14. Am J Cardiol

1988;62:52 B-568. 15. Appl Pathol 1983:1:89-96. 16. Proc Soc Exp Biol Med

1971:136:1216-1221.17. Jpn JPharmacol 1986:41:211-222

18. Am J Cardiol 1986:57:29H-35H. and/or animal in vivo data sug. unique modes of action ${ }^{\dagger}$

\section{Inhibits the oxidative modification of $\boldsymbol{L D L}^{4-10}$}

- Modified (cytotoxic) LDL may play a role in foam cell formation ${ }^{4-10}$

-foam cell formation is an initial step in atherosclerotic plaque development ${ }^{4-10}$ - Inhibits development of atherosclerotic lesions in animals $\$ 6,8$

†Data are only used to explain the unique modes of action of Lorelco; no clinical benefit is implied.

Lorelco is not an innocuous drug and strict attention should be paid to the Indications, Contraindications, Warnings, and Precautions sections of Prescribing Information. 


\section{EVELS}

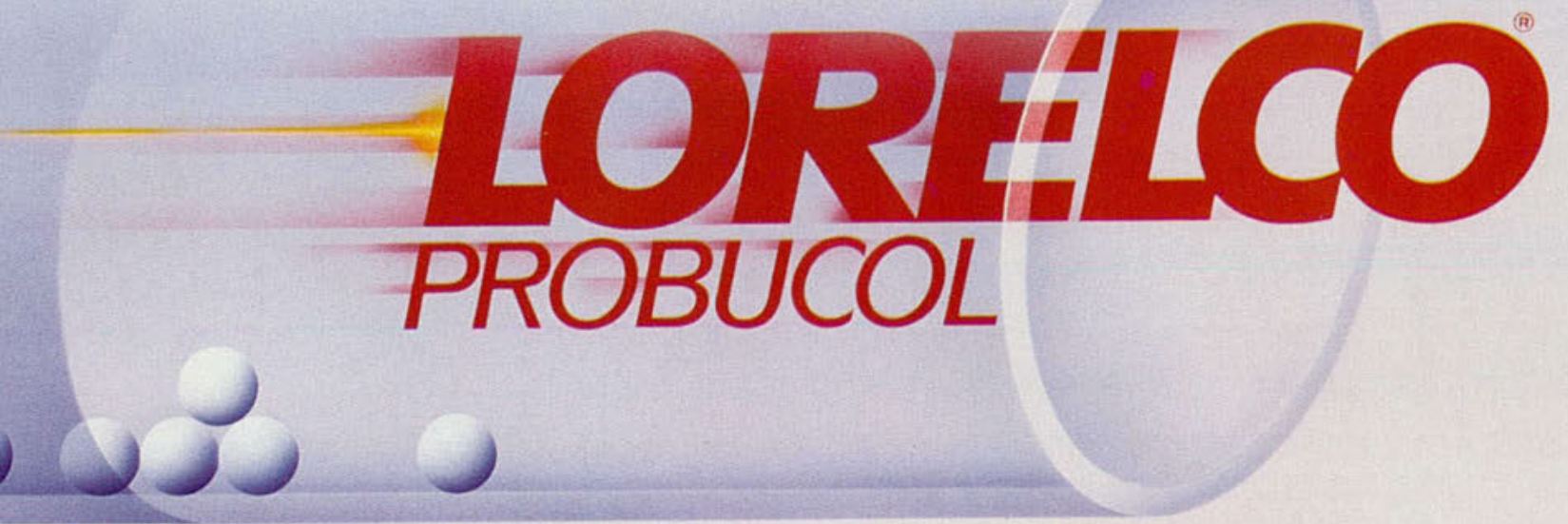

Recent in vitro studies and human and/or animal in vivo data suggest unique modes of action ${ }^{\dagger}$

\section{Enhances HDL-mediated reverse cholesterol transport $\$ 3,11-14$}

- Lorelco has been shown to regress atherosclerotic lesions in animals $\$ 15-17$

- The effects of probucol on HDL-cholesterol may reflect improved dynamics of HDLmediated reverse cholesterol transport $1 / 3,12,14,18$

$\ddagger$ See Contraindications, Warnings, and Animal Pharmacology and Toxicology.

§These effects of probucol on LDL (increase in catabolic rate) and HDL-cholesterol may be linked to the observed increased excretion of fecal bile acids, a final metabolic pathway for elimination of cholesterol from the body. (See Clinical Pharmacology.)

//The probable benefits obtained from $L D L-$ cholesterol reduction must be weighed against the possible risk of a reduction in $\mathrm{HDL}$-cholesterol when assessing the response of patients to probucol. If satisfactory lipid alteration is not achieved, the drug should be discontinued. (See Precautions.)

\section{TAKES YOU TO THE NEXT LEVEL OF CHOLESTEROL CONTROL}




\section{Lorelco ${ }^{\circledR}$ Tablets (probucol) \\ CAUTION: Federal law prohibits dispensing without prescription.}

DESCRIPTION: Lorelco (probucol) film-coated tablets for oral administration contain $250 \mathrm{mg}$ or $500 \mathrm{mg}$ of probucol pe:

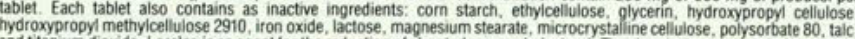
and titanium dioxide. Lorelco is an agent for the reduction of elevated serum cholesterol. The chemical name is $4,44^{\prime}-1(1-$ methyl.

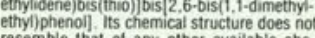
resembie that of any other available cho-

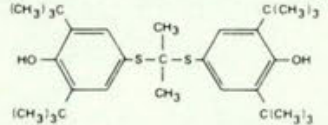

CLINICAL PHARMACOLOGY: Lorelco lowers total serum cholesterol and has relatively little effect on serum triglycerides.
Patients responding to probucol exhibit a decrease in low-density lipoprotein (LDL) cholesterol. Cholesterol is reduced not onity int the LDL fraction, but also in the high-density lipoprotein (HDL) fraction with proportionately greater effect on the high-density portion. Epidemiologic studies have shown that both low $\mathrm{HDL}$-cholesterol and hiog $\mathrm{L} L \mathrm{LL}$-cholesterterol are independent risk tactors
lor coronary heart disease. The risk of lowering $\mathrm{HDL}$-cholesterol while lowering $\mathrm{Lb}$-cholesterol remains unknown. There is little or no effect reported on very low-density lipoprotein (VLDL).

Studies on the mode of action of Lorelco indicate that it increases the fractional rate of LDL catabolism. This effect may be linked oreico also exhibits inhibition of early stages of cholesterol boic path way for the eimininaton of cholesterol from the body.

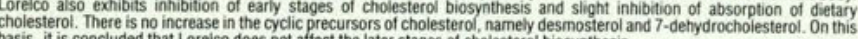
basis, it is concluded that Loreico does not affect the later stages of cholesterol biosynthesis.

Absorption of Lorelco from the gastrointestinal tract is limited and variable. When it is administered with food, peak blood levels gradually increase over the first three to four months and thereatter remain tairly constant in 116 patients treated lor periods of three months to one year, the mean blood level was $23.6 \pm 17.2 \mathrm{mcg} / \mathrm{mL}( \pm \mathrm{S} .0$.$) ranging 10.78 .3 \mathrm{mcg} / \mathrm{mL}$. Levels observed after seven years of treatment in 40 patients yielded an average vaiue of $21.5 \pm 16.5 \mathrm{mcg} / \mathrm{mL}( \pm \mathrm{S}$. D. . ranging
to $62.0 \mathrm{mcg} \mathrm{mL}$. In a separate study in eight patients, blood levels averaged $19.0 \mathrm{mcg} / \mathrm{mL}$ at the end of $12 \mathrm{month}$ of treattment.
Six weeks atter cessation of therapy, the average had tallen by $60 \%$. After six months, the average had tallen by 80\%

In December 1984, a National Institutes of Health Consensus Development Conference Panel1 concluded that lowering definitely corateary heart disease. The effect of probucol-induced reduction of serum cholesterol or thiglycerise levels, or reduction of
HDL-cholesterol levels on morbidity or mortality due to coronary heart disease has not been established.

INDICATIONS AND USAGE: Serious animal toxicity has been encountered with probucol. See WARNINGS and ANIMAL
PHARMACOLOGY AND TOXICOLOGY sections. Probucol is not an innocuous drug and strict attention should be paid to the INDICATIONS, CONTRAINDICATIONS, and WARNINGS.

Drug therapy should not be used for the routine treatment of elevated blood lipids for the prevention of coronary heart disease Dietary therapy specific for the type of hyperlipidemia is the initial treatment of choice. Excess body weight may be an important disease such as hypothyroidism or diabetes melitus should be looked for and adequately treated. The use of drugs should be considered only when reasonable attempts have been made to obtain satisfactory results with nondrug methods. If the decision ultimately is to use drugs, the patient should be instructed that this does not reduce the importance of adhering to diet. The selection of patients for cholesterol-lowering drug therapy should take into account other important coronary risk factors
such as smoking. hypertension, and diabetes mellitus. Consideration should be given to the efficacc, salety, and compliance
factors for each of the cholesterol-lowering drugs prior to selecting the one most appropriate for an individual patient Lorelco may be indicated for the reduction of elevated serum cholesterol in patients with primary hypercholesterolemia (Types
lla and $I 16$ hyperlipoproteinemia). ${ }^{2}$ whose elevated LLL-cholesterol has not responded adequately to diet, weight reduction, and control of diabetes mellitus. Loreico may be useful to lower elevated LDL-cholesterol that occurs in those patients with combined hypercholesterolemia and hypertriglyceridemia (Type IIt) due to elevation of both LDL and VLDL, but it is not cholesterol represents a primary lipid disorder, it should be determined that patients being considered for treatiment with Loreico have an elevated LDL-cholesterol as the cause for an elevated total serum cholesterol. This may be particularly relevant for patients with elevated triglycerides or with markedly eievated $\mathrm{HOL}$-cholesterol values, where non-LDL fractions may contribute
significantly to total cholesterol levels without apparent increase in cardiovascular risk. In most patients, LDL-cholesterol may
be estimated according to the following equation Ltholesterol = Total chole

$-[(0.16 \times$ triglycerides $)+$ HDL-cholestero $]$

When total triglycerides are greater than $400 \mathrm{mg} / \mathrm{dL}$, this equation is less accurate. In such patients, LDL-cholesterol may be It is not always possible to predict from the lipoprotein type or other factors which patients will exhibit favorable results. Lipid

The effect of probucol-induced reduction of serum cholesterol or triglyceride levels, or reduction of HDL-cholesterol levels on

CONTRAINDICATIONS: (See also WARNINGS and PRECAUTIONS.) Lorelco is contraindicated in patients who are known to findings suggestive of serious ventricular arritithmias or with unexplained syncope or syncope of cardiovascular origin. Lorelco is contraindicated in patients with an abnormally long OT interval.

WARNINGS: SERIOUS ANIMAL TOXICITY HAS BEEN ENCOUNTEREO WITH PROBUCCOL IN RHESUS MONNEYS FED AN
ATHEROGENIC DIET AND IN BEAGLE DOGS. (SEE ANIMAL PHARMACOLOGY AND TOXICOLOGY SECTION.)

Prolongation of the QT interval can occur in patients on Lorelco. Serious arrhythmias have been seen in and a concomitant antiarrhythmic drug. The following precautions are deemed prudent:

1. Patients should be advised to adhere to a low cholesterol, low fat diet at the start of treatment with Lorelco and throughout the

2. An ECG should be done prior to starting treatment and repeated at appropriate intervals during treatment. If an abnormally
long QT interval is observed, the possible benefits and risks should be carefully considered before making a decision to

Lorelco therapy should be discontinued or not started if the QT interval at an observed heart rate on a resting ECG is

\begin{tabular}{ccc}
\multirow{2}{*}{$\begin{array}{c}\text { Observed Heart Rate } \\
\text { (beats/min) }\end{array}$} & \multicolumn{2}{c}{$\begin{array}{c}\text { OT Interval in sec (15\% above the } \\
\text { upper limit of normal) }\end{array}$} \\
\cline { 2 - 3 } & Males & Females \\
\hline 40 & 0.56 & 0.58 \\
60 & 0.52 & 0.53 \\
70 & 0.49 & 0.50 \\
80 & 0.45 & 0.47 \\
86 & 0.43 & 0.44 \\
92 & 0.42 & 0.43 \\
100 & 0.40 & 0.40 \\
109 & 0.39 & 0.38 \\
120 & 0.37 & 0.36 \\
133 & 0.36 & 0.35
\end{tabular}

-Values calculated from Burch GE, Winsor T. A primer of electrocardiography. Philadelphia, PA: Lea and Febiger; 1958; D.
272 (Table 6).

3. Patients developing unexplained syncope or syncope of cardiovascular origin should have Lorelco therapy discontinued and
should have ECG surveil lance.

4. Drugs that prolong the QT interval are more likely to be associated with ventricular tachycardia atter:
a. An increase in the dose of the drug.

a. An increase in the dose of the drug.
and phenothiazines).

c. Hypokalemia or hypomagnesemis.

d. Severe bradycardia due to intrinsic heart disease or drug effects on the atrial rate (beta-blockers) or AV block (digoxin)

The use of Loreico in patients receiving any of these drugs should be based on the conclusion that titernate methods ol hypocholesterolemic therapy are either ineffective or no

The following conditions should be resolved or corrected prior to initiation of therapy with Lorelco:

a. Hypokalemia

b. Hypomagnesemia

Severe bradycardia due to intrinsic heart disease or drug effects on the atrial rate (beta-blockers) or AV block (digoxin) PRECAUTIONS

General: Before instituting therapy with Lorelco, adequate baseline studies should be performed to determine that the patien

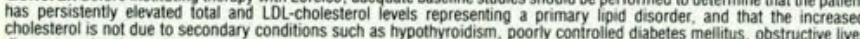
disease, nephrotic syndrome, or dyysproteinemilas. Serum lipid leveis, including HDL-cholesterol, should be determined after an
overnight fast before treatment, during an adeguate trial of diet and weight reduction therapy pror to addition of drug therapy and periodically during combined diet and drug therapy, including assessment during the firsy prior to addition of d frug therapy. A tavorable trend in lipid levels should be evident during the first three to four months of administration of Lorelco, and satisfactory lipid alteration is not achieved, the drug should be discontinued. Lorelco lowers serum total and LDL-cholesterol,
and also lowers $\mathrm{HDL}$-cholesterol in most patients with elevated LDL-cholesterol. Epidemiologic studies within hyper-

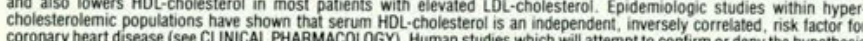
coronary heart disease (see CLINICAL PHARMACOLOGY). Human studies which will attempt to confirm or deny the hypothesis
that drug-induced alteration in HOL-cholesterol affects cardiovascular risk are currently under evaluation. It is not know whether Lorelco-induced reduction of serum HDL-cholesterol will aftect cardiovascular risk since no long-term, controlled
clinical trials of Lorelco for the prevention of coronary heart disease, similar to the LRC-CPPT (see CLINICAL STUDIES), have clinical trials of Lorelco for the prevention of coronary heart disease, similar to the LRC-CPPT (see CLINICAL STUDIES) have
been performed. The probable benefits obtained from LDL-cholesteroi reduction must be weighed against the possibie risk of reduction in $\mathrm{HOL}$-cholesterol when assessing the response
alteration is not achieved, the drug should be discontinued.
Information for Patients: The patient should be instructed to adhere to a prudent diet. Females should be cautioned ag:-
eecoming pregnant for at least six months after discontinuing Loreico and should not breast-feed their infants during the with Lorelco

Laboratory Tests: The physician should schedule periodic blood lipid determinations and periodic ECGs. (See WARNIN Elevations of the serum transaminases (SGOT, SGPT), bilirubin, alkaline phosphatase, creatine phosphokinase, uric acid . b urea nitrogen, and biood glucose above the normal range were observed on one or more occasions in various patients tre
with Lorelco. Most often these were transient andior could have been related to the patient's clinical state or other mode

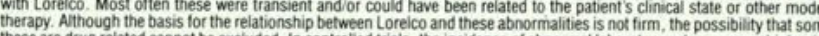
pase are drug related cannot be excluded. In controlied trials, the incidence of abnormal laboratory values was no higher signs consistent with the abnormal laboratory tests develop, or if systemic manifestations occur, Lorelco should be dis

Drug Interactions: The addition of clofibrate to Lorelco is not recommended, since the lowering effect on mean serum ie
of either LDL or total cholesterol is generally not signficantly additive and, in some patients, there may be a pronour

Neither oral hypoglycemic agents nor oral anticoagulants alter the effect of Lorelco on serum cholesterol. The dosage of

Monkeys fed a high fat, high cholesterol diet admixed with probucol exhibited serious toxicity. (See WARNINGS and ANI
PHARMACOLOGY AND TOXICOLOGY sections.) Prolonation of the OT inter PHARMACCLOGY AND TOXICOLOGY sections.) Prolongation of the OT interval can occur in patients on Lorelco and ser
arrmythmias have been seen in association with an abnormally long OT interval in patients on Loreico. The addition of a seC drug that prolongs the OT interval (including tricyclic antidepressants, class I and ill ants
increase the risk of serious arrtythmia. (See CONTRAINDICATIONS AND WARNINGS.)

Carcinogenesis, Mutagenesis, Impairment of Fertility
In chronic studies of two years' duration in rats, no toxicity or carcinogenicity was observed. These results are consiste Pregnancy
Terafogenic Effects

Pregnancy - Category B: Reproduction studies have been performed in rats and rabbits at doses up to 50 times the hu
dose, and have revealed no evidence of impaired fertility or harm to the fetus due to probucol. There are, however and well-controlled studies in pregnant women. Because animal reproduction studies are not always predictive of response, this drug should be used during pregnancy only if clearly needed. Furthermore, if a patient wishes to bec pregnant, it is recommended that the drug be withdrawn and birth control procedures be used for at least six months beca Labor And Delivery: The effect of Lorelco on human labor and delivery is unknown.

Nursing Mothers: It is not known whether this drug is excreted in human milk, but it is likely, since such excretion has Peditric Use.

Pediatric Use: Safety and effectiveness in children have not been established.

ADVERSE REACTIONS

Gastrointestinal

Candiovas oose stools, flatulence, abdominal pain, nausea, vomiting, indigestion, gastrointestinal bleeding

prolongastion of the QT interval on ECG, syncope, ventricular arrthythmias (ventricular tachycardia, torsades de po
ventricular fibrillation). sudden death

Neurologic

Hemacticiness, paresthesia, insomnia, tinnitus, peripheral neuritis

eosinophilia, low hemoglobin and/or hematocrit, thrombocytopenia

Dermatologic
rash, pruritus, ecchymosis, petechiae, hyperhidrosis, fetid sweat

Genitourinary

Ophthaimic

conjunctivitis, tearing, blurred vision

enlargement of multinodular goiter

Other

diminished sense of taste and smell, anorexia, angioneurotic edema

DRUG ABUSE AND DEPENDENCE: No evidence of abuse potential has been associated with Loreico, nor is OVER e psychological or physical dependence in humans.

DVEROOSAGE: There is a single report of a 15-kg, three-year-old, male child who ingested $5 \mathrm{~g}$ of probucol. Emesis
nduced by ipecac. The child remained well, apart from a breel episode of loose stools and flatulence. № specific intorma is avaliable on the treatment of overdosage with Lorelco and no specific antidote is available. Probucol is not dialyza Treatment is symptomatic and supportive. Probucol has shown no identfiable acute toxicity in mice and rats. In
animals the $L Q$, (oral) is in excess of 5 g/kg of body weight DOSAGE AND ADMINISTRATION: For adult use only. The recommended and maximal dose is $1000 \mathrm{mg}$ daily give
two divided doses of $500 \mathrm{mg}$ each (two $250 \mathrm{mg}$ tablets or one $500 \mathrm{mg}$ tablet) with the moming and evening meals. HOW SUPPLIED: $250 \mathrm{mg}$ round, white, film-coated tablets imprinted with either the DOW diamond trademark ove
code number 51 or LORELCO 250. Bottles of 120 (NDC 0068-0051-52)

$500 \mathrm{mg}$ capsule-shaped, white, film-coated tabiets, marked LORELCO 500. Bottles of 100 (NDC 0068-0053-61) Keep well closed. Store in a dry place. Avoid excessive heat. Dispense in well-closed light-resistant containers with

ANIMAL PHARMACOLOGY AND TOXICOLOGY: in rhesus monkeys. administration of probucol in diets contain
unusually high amounts of cholesterol and saturated tat resulted in the death of four of eight animals after several wh Premonitory syncope was trequently observed and was associated with a pronounced prolongation of the QT intervals ( 3 $50 \%$ longer than that observed in untreated monkeys). Serum levels of probucol greater than $20 \mathrm{mcg} / \mathrm{mL}$ were gener

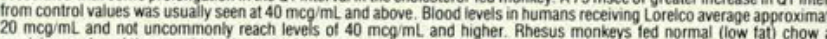
eceiving probucol three to thirty times the human dose equivalent achieved blood levels only one-third those of many hur subjects. No adverse effects were detected in these monkeys over an eight-year period of continuous drug administration

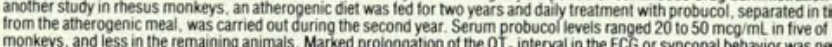

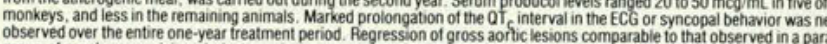
group of monkeys receiving cholestyramine was seen in animals receiving probucol. It should be emphasized that both $H$ cholesterol and $\mathrm{LL}$-cholesterol were markedly reduced in this regression study. During the performance of a two-year chro

Subsequent experiments have indicated that probucol sensitizes the canine myocardium to epinephrine, resulting in ventrict
brillation in many dogs. Among the animal species in which prow onilation in many dogs. Among the animal species in which probucol has been studied, the dog is peculiar with respect to
henomenon of sudden death due to the sensitization of the myocardium to epinephrine. In contrast to findings in the of inections of epinephrine to probucol-treated monkeys did not induce ventricular fibrillation.
injection

In other studies, monkeys were given probucol either before and after, or only after myocardial intarction was induced coronary artery ligation. In these studies, there was no difference between probucol- and placebo-treated groups with respec
either survival or detailed blind quantitation of myocardial changes (gross and histopathologic)

Probucol has shown no identifiable toxicity in mice and rats. In these animals, the LDso (oral) is in
weight. In chronic studies of two years' duration in rats, no toxicity or carcinogenicity was observed

From studies in rats, dogs, and monkeys, it is known that probucol accumulates slowly in adipose tissue. Approximately 90 probucol administered orally is unabsorbed. For that which is absorbed, the biliary tract is the major pathway for clearance fr Myocardial injury was produced in various groups of rats by one of the following procedures: aortic coarctation, coron
ligation, of cobalt or isoproterenol injection. After probucol administration, no deleterious effects related to treatment occur as measured by survival and microscopic examination of myocardial damage.

Probucol was administered to minipigs beginning ten days before ligation of coronary artery and continued for 60 days at surgery. Challenge with ep
probucol-treated minipigs.

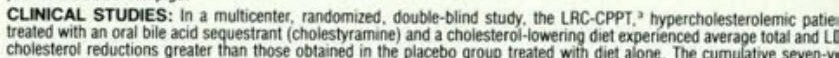
cholesterol reductions greater than those obtained in the placebo group treated with diet alone. The cumulative seven-yn
inciesence of the primary end point - combined incidence of definite CHD death and or definite nontatal myocardial intarction was $7 \%$ in the cholestyramine group and $8.6 \%$ in the placebo group. This was a 19\% reduction in risk ( $P$ less than 0.05 , sing intarction.

The subjects included in the study were middle-aged men ( $35-59$ years old) with serum cholesterol levels at least $265 \mathrm{mg} / \mathrm{dL}$
no previous history of heart disease. It is not clear to what extent these findings can be extrapolated to other segment' hypercholesterolemic population not studied.

The bile acid sequestrant, cholestyramine, was used in the above trial. Caution should be exercised in extrapolating these resu to Lorelco since it differs from cholestyramine with regard to its mode of action, spectrum of cholesterol-lowering poten
effect on HDL-cholesterol. and possible toxicity. The effect of probucol-induced reduction of serum cholesterol levels REFERENCES

1. Consensus Development Panel. Lowering blood cholesterol to prevent heart disease. JAMA. 1985; 253-2080-2086 2. Fredrickson DS, Leyr RI, Lees. RS. Fat transport in lipoproteins - an integrated approach to mechanisms and disorders
Engl J Med. 1967: 276:34-44. The Lipid Research Clinics Program. The Lipid Research Clinics coronary primary prevention trial results: I. Reduction
incidence of coronary heart disease. JAMA. 1984;251:351-364 Product Information as of June, 1988

MERRELL DOW PHARMACEUTICALS INC
Subsidiary of The Dow Chemical Compan

Merrell Dow 
TABLE 1. FREQUENCY OF SIGNS AND SYMPTOMS ENDORSED BY SOMATIZATION DISORDER (SD) PATIENTS (ADAPTED FROM PERLEY AND GUZE 28 ).

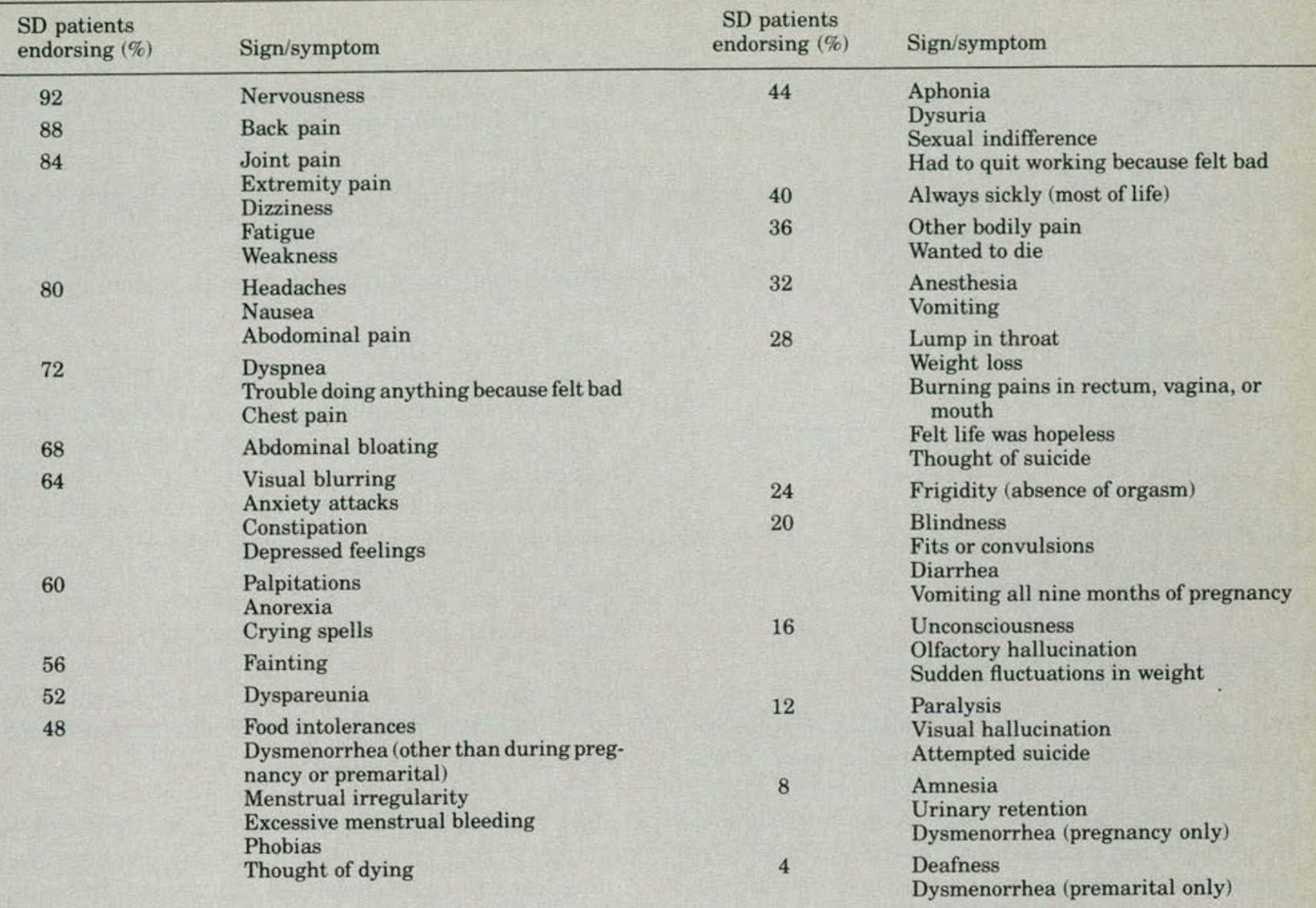

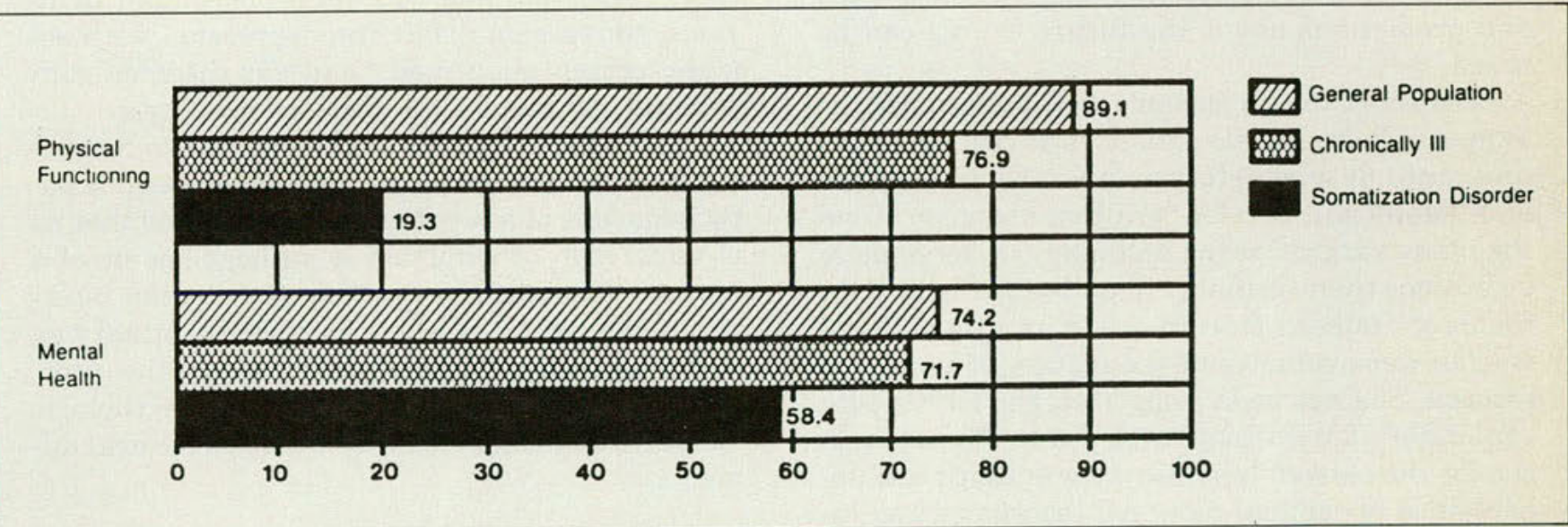

Fig 1. Average mental health and physical functioning scores of 41 SD patients on the Rand Health Status Measures compared to general population norms and a medically ill (chronic obstructive pulmonary disease and diabetes) sample (data adapted from Smith and associates $^{29}$ ).

ment; at best, they are temporarily successful. ${ }^{30-32}$ An SD patient will "develop" symptoms in which the physician shows most interest. For example, if the physician is a gastroenterologist, gastroin- testinal symptoms will predominate in the clinical picture; with a cardiologist, chest pain is a likely complaint. Such patients seem unconsciously, although exquisitely, responsive to the physician's 


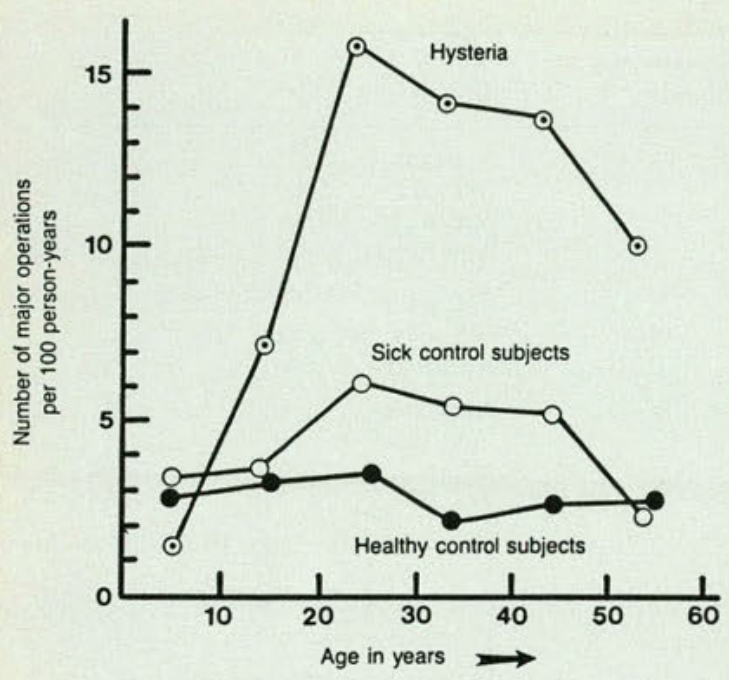

Fig 2. Frequency of operations for $S D$ (hysteria), medically ill, and healthy control subjects as a function of age (data adapted from Cohen and coworkers ${ }^{33}$ ).

most subtle nonverbal communication of interest.

A good standard question to ask oneself in understanding and managing such patients is: "Why this complaint, and why now?" A thorough understanding of the patient's psychosocial history, interpersonal environment, and events temporally related to the onset of the latest symptoms will provide the practitioner with the raw data on which a psychodynamic explanation can be constructed and predictions about the future course can be based.

Because of the physician's well-intentioned attempts to help, the SD patient is at risk for recurrent multiple exploratory or "therapeutic" surgeries. ${ }^{33}$ Many will develop "gridiron abdomen" from the many surgical scars, and many undergo more operations than verifiably ill patients (Fig 2) ${ }^{33}$ (In the most dramatic case known to us, a 34-year-old woman was evaluated at the request of a surgical resident. She was undergoing a workup for her 14th exploratory laparoscopy in 16 years. The sole reason for the current laparoscopy was continued unexplained abdominal pain. All laboratory and radiologic findings were normal. Consultation with the attending surgeon and referring physician led to cancellation of the operation. The physician reported feeling pressured to "do something" with the patient and therefore referred her for diagnostic surgery to "reassure" her.)

Somatization disorder has been demonstrated to be a unique and clinically useful nosologic category. ${ }^{34,35}$ In the original studies testing the prog- nostic utility of SD, five-year follow-up of patients whose condition originally was diagnosed as conversion or hysteric reactions revealed that $50 \%$ later were found to have true medical illness, which probably caused the original symptomatic picture. ${ }^{28,36}$ By using the original SD criteria, ${ }^{28,34-39}$ the probability of such an outcome is reduced to $10 \% 12,35$; that is, $90 \%$ of patients meeting the original criteria ( $82 \%$ of those meeting the DSM III criteria) will not have medical illness develop but will remain objectively healthy over the ensuing five years.

The original criteria ${ }^{28,34-39}$ required 25 symptoms spread across nine of ten body systems. The requirement for wide systemic spread was based originally on the premise that any true physical disease, even if subclinical, most likely would be limited to one or a few systems. But reevaluation of the initial data has revealed that a higher degree of diagnostic sensitivity is accomplished, with no real loss of specificity, by requiring 13 positive symptoms and dropping the requirement of spread across body systems. ${ }^{9}$ Several checklists ${ }^{40-44}$ exist to aid the primary care practitioner in diagnosing the somatization disorder. But the currently accepted diagnostic criteria are contained in Table $2 .{ }^{9}$

The practitioner always must be alert to the possibility of an organic cause for the patient's discomfort. Other psychologic disorders also must be considered in the differential diagnosis. These include, but are not limited to, anxiety disorders (especially those characterized by recurrent panic attacks), schizophrenia with multiple somatic delusions, conversion disorders, depression with somatic presentation, and factitious disorder with physical symptoms (Münchausen syndrome).

Two useful axioms for the practitioner to remember are that no psychiatric sign or symptom is pathognomonic of a psychiatric disorder, and that no physical sign or symptom is pathognomonic of a medical disorder. The practitioner who can incorporate these principles into his or her habitual way of conceptualizing patients may prevent the incorrect treatment of medical illnesses as psychologic disorders and psychologic disorders as medical ailments.

\section{Complications}

Many of the most serious complications of SD are iatrogenic. Aggressive, well-intended attempts of multiple physicians to diagnose and treat various symptoms places the patient at risk for the routine complications of surgery (anesthetic-induced sudden death, infection, adhesions) and abuse of psychoactive substances (analgesics, soporifics, anxiolytics, antidepressants). Data indicate that SD 
patients expend up to 14 times as much as the general population on physician services and nine times as much on total health care. ${ }^{19}$

SD patients generally have chaotic work histories $^{45}$ because they differ with employers about time off from work for bed rest and physician visits (an average of seven days a month are missed for illness ${ }^{29}$ ), abuse of insurance coverage (average medical bill of $\$ 4,700$ per year ${ }^{27}$ ), and a lesser work load because of weakness, fatigue, and illness. Similar conflicts will arise with spouses and offspring, who alternately feel resentment at or compassion for the patient's suffering. As the patient's history unfolds, significant others come to perceive themselves as manipulated or abused by the patient. Sexual avoidance or dysfunction is common among these patients and is another source of marital strain.

Occasionally, SD patients experience depressive symptoms of sufficient severity to cause incapacity. As with any depressed patient, suicidal potential must be monitored continually. Foreseeable interpersonal crisis must be the focus of counseling to minimize the probability of suicide attempts.

\section{Management and treatment}

Somatization disorder patients often evoke frustration in physicians because these patients are viewed as not really sick and therefore in violation of the implicit physician-patient social compact. To help protect these patients from their own harmful proclivities, the primary care physician must recognize that the behavior is directed entirely unconsciously. Because patients are unable or unwilling to consider psychogenic explanations, they can not attribute causality of their distress to psychosocial events. ${ }^{46}$ Even the most subtle display of frustration or direct challenge to the validity (reality) of the patient's illness is counterproductive and most likely will lead to the patient seeking help elsewhere.

It is imperative that the physician presents a sympathetic demeanor. Regularly scheduled visits will reduce the patient's need to create symptoms. Physical examinations can reassure the patient that complaints are being taken seriously. Routine screening tests (fasting urine glucose tests, serum lipid determinations, Papanicolaou smears, mammograms) conducted when appropriate and when the patient is most demanding and distressed can both reassure the patient of the physician's concern and detect malignant conditions in their early phases.

Not only is it possible for such patients to have objectively verifiable (real) illnesses develop, but such patients are, in fact, suffering, and they are
TABLE 2. DIAGNOSTIC CRITERIA FOR SOMATIZATION DISORDER (ADAPTED FROM SPITZER ${ }^{9}$ ).

(A) A history of many physical complaints or a belief that one is sickly, beginning before the age of 30 and persisting for several years.

(B) At least 13 symptoms from the list below. To count a symptom, the following criteria must be met: No organic pathologic findings or, when there is related organic disease, the complaint or resulting social or occupational impairment is grossly in excess of what would be expected from the physical findings; the symptom has not occurred only during a panic attack; and the symptom has caused the patient to take medicine (other than over-the-counter pain medication), visit a doctor, or alter life-style.

\section{Symptom list}

- Gastrointestinal symptoms:

Vomiting (other than during pregnancy) *

Abdominal pain (other than when menstruating)

Nausea (other than motion sickness)

Bloating (gaseous)

Diarrhea

Intolerance for several different foods

- Pain symptoms:

Pain in extremities*

Back pain

Joint pain

Pain during urination

Other pain (excluding headaches)

- Cardiopulmonary symptoms:

Shortness of breath when not exerting oneself*

Palpitations

Chest pain

Dizziness

- Conversion/pseudoneurologic symptoms:

Amnesia*

Difficulty swallowing*

Loss of voice

Deafness

Double vision

Blurred vision

Blindness

Fainting or loss of consciousness

Seizure convulsion

Trouble walking

Paralysis or muscle weakness

Urinary retention or difficulty urinating

- Sexual symptoms (for the major part of the patient's life after the beginning of opportunities for sexual activity):

Burning sensation in sexual organs or rectum (other than during intercourse $)^{*}$

Sexual indifference

Pain during intercourse

Impotence

- Female reproductive symptoms (judged by the patient to occur more frequently or severely than in most women): Painful menstruation*

Irregular menstrual periods

Excessive menstrual bleeding

Vomiting throughout pregnancy

* These seven items may be used to screen for SD. The presence of two or more of these items suggests a high likelihood of the disorder.

acutely talented at detecting physician doubt as well. It may help the physician to keep in mind Wilder Penfield's maxim: "Assume the pain is real (that is, consciously experienced by the patient even if not a result of tissue damage) unless you 
have incontrovertible proof that the patient is malingering." Certainly our current state of ignorance regarding mind-brain/body relationships justifies such a stance.

The primary care physician should have an objective medical reason for ordering consultation or expensive or invasive diagnostic tests for such patients. Such a management strategy reduces health care costs by about $50 \% .47,48$

In one study, ${ }^{48}$ a single psychiatric consultation led to significantly reduced ordering of expensive diagnostic tests. Median quarterly total health care charges dropped from $\$ 765$ to $\$ 158$, and the annual number of days of hospitalization dropped from 6.4 to 2.4. However, outpatient visits did not decrease, because part of the recommended management protocol was scheduling regular visits at four- to six-week intervals.

The deliberate avoidance of hospitalizations, diagnostic procedures, and surgeries may evoke some malpractice anxiety for the primary care physician. Once the SD patient's condition is diagnosed, it must be remembered that more care is not necessarily better care. However, new symptoms need to be taken seriously for two reasons: (1) to reassure the patient and confirm the validity and seriousness of her suffering; and (2) to detect any objectively verifiable illness that might arise.

The use of psychotropic medications for SD patients requires more caution than usual. SD patients probably make up a significant proportion of iatrogenic substance abusers. They are prone to self-medicating and to misinterpreting the signs and symptoms of withdrawal from prescribed medications (for example, rebound insomnia following withdrawal of soporifics); thus, they remedicate themselves to cope with the absence of the regimen.

Repeated admonitions regarding the risks of developing a dependence or abuse disorder are helpful if such a development is presented as one of the frequent complications of being sickly. The fact that treatment sometimes can be worse than living with the illness should be emphasized. Lowdose, short-term prescription of psychotropic agents may, because of the placebo effect or the implicit social communication that "this is real sickness, because the doctor gave me medicine," also reassure the patient who is in a symptom-aggravating interpersonal crisis.

Insight-oriented/cognitive psychotherapy may be of assistance in enabling patients to attribute their physical symptoms to interpersonal and emotional causes, but it must be presented to the patient as an adjunct to medical care. Framing the patient's illness as stress-caused or aggravated, rather than emotional or mental, somtimes can make counseling an acceptable therapy. ${ }^{47,49}$ In one study ${ }^{47}$ of a short-term (six to 12 sessions) treatment program for Medicaid and Blue Cross abusers (patients who fell into the top $10 \%$ of medical charges with no verifiable illness), medical costs decreased by $47 \%$.

The practitioner's primary goal with such patients should be prevention of iatrogenic harm. By providing a sympathetic ear and confirmation of the legitimacy and seriousness of the patient's suffering, the physician can avoid having the patient "doctor shop." Such physician-shopping eventually results in receipt of prescription drugs, drug abuse, or aggressive, expensive, and risky diagnostic procedures. ${ }^{29,48-52}$ Once this primary goal is accomplished, the task of gently suggesting the role of psychologic determinants can be undertaken.

\section{Summary}

Somatization disorder is characterized by a history of multiple somatic complaints that are unverified by objective evidence. These patients, typically female, are prone to doctor-shopping, prescription abuse, and multiple, expensive, and unnecessary workups. Once the diagnosis is made, SD patients are best managed by sympathetic primary care physicians who are conservative in their pursuit of medical explanations for the patient's complaints. Somatization disorder patients generally are resistant to psychologic explanations for their problems, but some will accept referral for counseling if it is presented as adjunctive to medical care and framed as treatment of "stress" rather than "emotional" or "mental" problems.

1. Blackwell B: Medical education and modest expectations. Gen $H$ osp Psychiatry 1985;7:1-3.

2. Beaber RJ, Rodney WM: Underdiagnosis of hypochondriasis in family practice. Psychosomatics 1984;25:39-43.

3. Jencks SF: Recognition of mental distress and diagnosis of mental disorder in primary care. JAMA 1985;253:1903-1907.

4. Pilowsky I: Abnormal illness behavior. Br J Med Psychol 1969;42:347351

5. Boring EG: A History of Experimental Psychology. Englewood Cliffs, NJ, Prentice-Hall, 1950.

6. Broad CD: The Mind and Its Place in Nature. London, Routledge and Kegan Paul, Ltd, 1925.

7. Ketterer MW: Awareness I: The natural ecology of subjective experience and the mind-brain problem revisited. J Mind Behav 1985;6:469513.

8. Warner JH: The Therapeutic Perspective: Medical Practice, Knowledge and Identity in America. Cambridge, Mass, Harvard University Press, 1986.

9. Spitzer RL (Chairman): Diagnostic and Statistical Manual of Mental Disorders, ed 3, revised. Washington, DC, American Psychiatric Press, 1987.

10. Casper RC, Redmond DE Jr, Katz MN, et al: Somatic symptoms in primary affective disorder: Presence and relationship to the classification of depression. Arch Gen Psychiatry 1985;42:1098-1104.

11. Sheehan DV: The Anxiety Disease and How to OvercomeIt. New York, Charles Scribner's Sons, 1984. 
12. Goodwin DW, Guze SB: Psychiatric Diagnosis ed 2. New York, Oxford University Press, Inc, 1974.

13. Gordon E, Kraivhin C, Kelly P, et al: The development of hysteria as a psychiatric concept. Compr Psychiatry 1984;25:532-537.

14. Monson RA, Smith GR Jr: Current concepts in psychiatry: Somatization disorder in primary care. $N$ Engl $J$ Med 1983;308:1464-1465.

15. Shapiro D: [Neurotic Styles]. New York, Basic Books, Inc, 1965.

16. Slavney PR, Teitelbaum ML, Chase GA: Referral for medically unexplained somatic complaints: The role of histrionic traits. Psychosomatics 1985;26:103-109.

17. Millon T: Disorders of Personality: DSM-III: AXIS II. New York, John Wiley \& Sons, Inc, 1981.

18. Briquet P: Trait Clinique et Therapeutique a l Hysterie. Paris, J.B. Baliere \& Fils, 1859.

19. DeGruy F, Columbia L, Dickinson P: Somatization disorder in a family practice. J Fam Pract 1987;25:45-51.

20. Arkonac O, Guze SB: A family study of hysteria. $N$ Engl $J$ Med 1963;268:239-242.

821. Cloninger CR, Reich T, Guze SB: The multifactorial model of disease transmission: III. Familial relationship between sociopathy and hysteria (Briquet's syndrome). Br J Psychiatry 1975;127:23-32.

22. Woerner PI, Guze SB: A family and marital study of hysteria. $\mathrm{Br} J$ Psychiatry 1968;114:161-168.

23. Bohman M, Cloninger CR, Von Knorring AL, et al: An adoption study of somatoform disorders: III. Cross-fostering analysis and genetic relationship to alcoholism and criminality. Arch Gen Psychiatry 1984;41:872877.

24. Cloninger CR, Guze SB: Hysteria and parental psychiatric illness. Psychiatr Med 1975;5:27-31.

25. Guze SB, Woodruff RA Jr, Clayton PJ: Hysteria and antisocial behavior: Further evidence of an association. Am J Psychiatry 1971;127:957960 .

26. Torgersen S: Genetics of somatoform disorders. Arch Gen Psychiatry 1986;43:502-507.

27. Smith GR Jr, Monson RA, Livingston RL: Somatization disorder in men. Gen Hosp Psychiatry 1985;7:4-8.

28. Perley MJ, Guze SB: Hysteria: The stability and usefulness of clinical criteria. N Engl J Med 1962;266:421-426.

29. Smith GR Jr, Monson RA, Ray DC: Patients with multiple unexplained symptoms: Their characteristics, functional health, and health care utilization. Arch Intern Med 1986;146:69-72.

30. Guze SB, Perley MJ: Observations on the natural history of hysteria. Am J Psychiatry 1963;119:960-965.

31. Purtell JJ, Robins E, Cohen ME: Observations on clinical aspects of hysteria: Quantitative study of 50 hysterical women and 156 control subjects. JAMA 1951;146:902-909.

32. White L, Tursky B, Schwartz GE (eds): Placebo: Theory, Research, and Mechanisms. New York, Guilford Press, 1985.

33. Cohen ME, Robins E, Purtell JJ, et al: Excessive surgery in hysteria: Study of surgical procedures in 50 women with hysteria and 190 controls. JAMA 1953;151:977-986.

34. Feighner JP, Robins E, Guze SB, et al: Diagnostic criteria for use in psychiatric research. Arch Gen Psychiatry 1972;26:57-63.

35. Spitzer RL, Endicott J, Robins E: Research diagnostic criteria: Rationale and reliability. Arch Gen Psychiatry 1978;35:773-782.

36. Guze SB: The diagnosis of hysteria: What are we trying to do? Am J Psychiatry 1967;124:491-498.

37. Slater E: Diagnosis of 'hysteria.' Br Med $J$ 1965;1:1395-1399.

38. Woodruff RA Jr: Hysteria: An evaluation of objective diagnostic criteria by the study of women with chronic medical illnesses. Br J Psychiatry 1967;114:1115-1119.

39. Woodruff RA Jr, Clayton PJ, Guze SB: Hysteria: Studies of diagnosis, outcome, and prevalence. JAMA 1971;215:425-428.

40. Guze SB: The role of follow-up studies: Their contribution to diagnostic classification as applied to hysteria. Seminars in Psychiatry 1970;2:392-402.

41. Reveley MA, Woodruff RA Jr, Robins LN, et al: Evaluation of a screening interview for Briquet syndrome (hysteria) by the study of medically ill women. Arch Gen Psychiatry 1977;34:145-149.

42. Woodruff RA Jr, Robins LN, Taibleson M, et al: A computer assisted derivation of a screening interview for hysteria. Arch Gen Psychiatry 1973;29:450-454.

43. Woodruff RA Jr, Clayton PJ, Guze SB: Hysteria: An evaluation of specific diagnostic criteria by the study of randomly selected psychiatric clinic patients. Br J Psychiatry 1969;115:1243-1248.

44. DeSouza C, Othmer E: Somatization disorder and Briquet's syndrome:
An assessment of their diagnostic concordance. Arch Gen Psychiatry 1984;41:334-336.

45. Zoccolillo M, Cloninger CR: Somatization disorder: Psychologic symptoms, social disability, and diagnosis. Compr Psychiatry 1986;27:65-73. 46. Ware JE Jr, Manning WG Jr, Duan N, et al: Health status and the use of outpatient mental health services. Am Psychol 1984;39:10901100 .

47. Turkington C: Project finds short-term psychotherapy cuts health costs. APA Monitor, July 1985, pp 3-4.

48. Smith GR Jr, Monson RA, Ray DC, et al: Psychiatric consultation in somatization disorder: A randomized controlled study. N Engl J Med 1986;314:1407-1413.

49. Budman SH, Demby A, Feldstein ML: Insight into reduced use of medical services after psychotherapy. Prof Psychol Res Pract 1984;15:353361.

50. Borus JF, Olendzki MC, Kessler L, et al: The 'offset effect' of mental health treatment on ambulatory medical care utilization and charges: Month-by-month and grouped-month analysis of a five-year study. Arch Gen Psychiatry 1985;42:573-580.

51. Rosen JC, Wiens AN: Changes in medical problems and use of medical services following psychological intervention. Am Psychol 1979;34:420431.

52. Barsky AJ: The paradox of health. N Engl J Med 1988;318:414-418.

From the Center for Behavioral Medicine, College of Osteopathic Medicine of Oklahoma State University, Tulsa.

Reprint requests to Dr Ketterer, Psychiatry, Henry Ford Hospital, 2799 West Grand Blvd, Detroit, MI 48202. 